\title{
The neurobehavioural rating scale: assessment of the behavioural sequelae of head injury by the clinician
}

\author{
HARVEY S LEVIN, * WALTER M HIGH, * KATHERINE E GOETHE, $\dagger$ \\ REBECCA A SISSON, $\ddagger$ JOHN E OVERALL,§ HOWARD M RHOADES,$\S$ \\ HOWARD M EISENBERG,* ZVI KALISKY,\| HOWARD E GARY*
}

From the Division of Neurosurgery, The University of Texas Medical Branch, Galveston, ${ }^{*}$ Texas, Department of Mental Health, Wilford Hall, United States Air Force Medical Center, Lackland Air Force Base, $\dagger$ Texas, Department of Psychological Nursing, University of California at San Francisco, San Francisco, $\ddagger$ California, Department of Psychiatry and Behavioral Sciences, University of Texas Health Science Center at Houston, Houston, $\S$ Texas, Department of Rehabilitation Medicine, Medical Center Del Oro, Houston, $\|$ Texas, USA

SUMMARY To investigate the inter-rater reliability and validity of the Neurobehavioural Rating Scale at various stages of recovery after hospitalisation for closed head injury, we studied 101 head trauma patients who had no antecedent neuropsychiatric disorder. The results demonstrated satisfactory inter-rater reliability and showed that the Neurobehavioural Rating Scale reflects both the severity and chronicity of closed head injury. A principal components analysis revealed four factors which were differentially related to severity of head injury and the presence of a frontal lobe mass lesion. Although our findings provide support for utilising clinical ratings of behaviour to investigate sequelae of head injury, extension of this technique to other settings is necessary to evaluate the distinctiveness of the neurobehavioural profile of closed head injury as compared with other aetiologies of brain damage.

Behavioural disturbance is frequently manifested by patients during the subacute stage of recovery from severe closed head injury. ${ }^{1-7}$ Residual behavioural problems are particularly debilitating sequelae of severe closed head injury which contribute immensely to chronic disability, ${ }^{8}$ impose a burden on the family ${ }^{9-16}$ and provide a challenge to rehabilitation. ${ }^{10}$ In contrast to a recent study ${ }^{17}$ showing that psychological status improves over time after initial diagnosis of a chronic medical illness (for example, cancer, diabetes), the psychopathology associated with severe closed head injury persists and may intensify over time..$^{91014}$ Although major alterations of personality after head trauma are generally confined to severe injury, ${ }^{291314}$ postconcussional symptoms (for example, headaches, dizziness, fatiguability, difficulty in concentration and memory) and associated emotional distress may frequently persist for at least 1 to 3 months following minor head

Address for reprint requests: Harvey $\mathrm{S}$ Levin, $\mathrm{PhD}$, Division of Neurosurgery, The University of Texas Medical Branch, Galveston, Texas 77550, USA.

Received 3 January 1986 and in revised form 11 April 1986. Accepted 17 April $198 \dot{6}$ injury. ${ }^{18-20}$ Administration of structured interviews and rating scales to relatives has elucidated the diversity of behavioural sequelae exhibited by head injured patients in various situations and the psychiatric repercussions imposed on family members. $^{9-1621}$ However, ratings by the clinicianinvestigator and self-reports by the patient can also be informative in assessing psychosocial outcome of closed head injury.

Self-administered personality tests such as the Minnesota Multiphasic Personality Inventory (MMPI) ${ }^{22}$ have disclosed a positive relationship between residual psychopathology and cognitive deficit after head injury and have characterised changes in emotional disturbance over time since injury. ${ }^{102324}$ Self-administered procedures are primarily useful to evaluate long term outcome of closed head injury rather than during the early posttraumatic period when severely injured patients are frequently unable to complete lengthy questionnaires because of confusion, attentional deficit, restlessness and agitation. Secondly, chronic patients who have sustained severe closed head injury may underestimate their behavioural problems, a bias which can compromise the accuracy of self-report data. ${ }^{13}$ 
Table 1 Demographic and clinical features of head injured patients*

\begin{tabular}{|c|c|c|c|c|c|}
\hline & & $\begin{array}{l}\text { Mild }+ \text { closed } \\
\text { head injury } \\
(n=29)\end{array}$ & $\begin{array}{l}\text { Moderate } \dagger \text { closed } \\
\text { head injury } \\
(n=25)\end{array}$ & $\begin{array}{l}\text { Severe closed } \\
\text { head injury } \\
\text { Consec. }(n=29)\end{array}$ & $\begin{array}{l}\text { Severe closed } \\
\text { head injury } \\
\text { Rehab. }(n=18)\end{array}$ \\
\hline $\begin{array}{l}\text { Age (yr) } \\
\text { Education (yr) } \\
\text { Sex (N) }\end{array}$ & $\begin{array}{l}\mathbf{X} \\
\text { SD } \\
\mathbf{X} \\
\mathbf{S D} \\
\mathbf{M} \\
\mathbf{F}\end{array}$ & $\begin{array}{r}23.4 \\
6.2 \\
11.7 \\
1.9 \\
21 \\
8\end{array}$ & $\begin{array}{r}27 \cdot 9 \\
8 \cdot 4 \\
11 \cdot 8 \\
2 \cdot 0 \\
19 \\
6\end{array}$ & $\begin{array}{c}23 \cdot 0 \\
8 \cdot 0 \\
11 \cdot 6 \\
2 \cdot 8 \\
23 \\
6\end{array}$ & $\begin{array}{c}20 \cdot 8 \\
4 \cdot 4 \\
12 \cdot 5 \\
1.9 \\
15 \\
3\end{array}$ \\
\hline $\begin{array}{l}\text { Type of Injury }(\mathbf{N}): \\
\text { Left } \\
\text { Right } \\
\text { Bilateral } \\
\text { Diffuse }\end{array}$ & & $\begin{array}{r}0 \\
0 \\
0 \\
29\end{array}$ & $\begin{array}{l}8 \\
9 \\
4 \\
4\end{array}$ & $\begin{array}{l}6 \\
8 \\
9 \\
6\end{array}$ & $\begin{array}{l}3 \\
3 \\
4 \\
8\end{array}$ \\
\hline $\begin{array}{l}\text { Stage of Recovery (N): } \\
\text { Subacute } \\
\text { Chronic } \\
\text { Injury-Test } \\
\text { Interval (days) } \\
\text { GCS Score (N) }\end{array}$ & $\begin{array}{l}X \\
\text { SD }\end{array}$ & $\begin{array}{c}20 \\
9 \\
17 \cdot 8 \\
4 \cdot 6\end{array}$ & $\begin{array}{l}23 \\
2 \\
62 \cdot 4 \\
27 \cdot 4\end{array}$ & $\begin{array}{c}20 \\
9 \\
367 \cdot 0 \\
98.9\end{array}$ & $\begin{array}{c}0 \\
18 \\
1640 \cdot 2 \\
372 \cdot 8\end{array}$ \\
\hline $\begin{array}{l}<8 \\
9-12 \\
13-15 \\
\text { Duration of Impaired Consciousness } \\
\text { (days) } \ddagger\end{array}$ & $\begin{array}{l}\mathbf{X} \\
\mathbf{S D}\end{array}$ & $\begin{array}{l}0 \\
0 \\
29 \\
0.0025 \\
0.0049\end{array}$ & $\begin{array}{c}0 \\
12 \\
13 \\
1 \cdot 2 \\
2 \cdot 9\end{array}$ & $\begin{array}{c}29 \\
0 \\
0 \\
13 \cdot 5 \\
17 \cdot 6\end{array}$ & $\begin{array}{c}18 \\
0 \\
0 \\
62 \cdot 7 \\
53 \cdot 5\end{array}$ \\
\hline
\end{tabular}

*CHI, GCS, Glasgow Coma Scale; Consec., consecutive cases; Rehab., cases studied while attending a residential programme for cognitive and psychosocial rehabilitation.

+Patients with GCS scores of 13-15 who had intracranial mass lesions were classified as moderate injuries.

fInterval from injury until patient obeyed commands.

A scale for the clinician or trained investigator to rate behavioural sequelae is a potentially useful adjunct in outcome studies and in documenting the clinical course of head injury. Although psychosocial features are incorporated in the global categories of quality of survival which comprise the Glasgow Outcome Scale, ${ }^{25}$ we are unaware of a scale developed specifically to assess behavioural changes following brain injury. Levin and his associates ${ }^{126}$ utilised the Brief Psychiatric Rating Scale (BPRS) ${ }^{27}$ to study the behavioural manifestations of closed head injury following resolution of posttraumatic amnesia (PTA) in consecutive admissions and one year after severe head injury. Ratings on BPRS scales measuring emotional withdrawal, conceptual disorganisation, motor retardation, unusual thought content, blunted affect, excitement and disorientation were sensitive to the duration of coma in a series in which the preponderance of cases were studied during their initial hospitalisation. ${ }^{1}$ Chronic disability after severe closed head injury was positively related to BPRS indices of thinking disturbance, emotional withdrawal and motor retardation. ${ }^{26}$ However, the degree of anxiety and depression was related to neither the overall quality of outcome nor the severity of acute injury.

While the BPRS has provided useful quantitative information on the behavioural sequelae of closed head injury, it was designed primarily for assessment of psychiatric disorders. Prominent neurobehavioural features of head injured patients such as disturbance of attention, memory deficit, diminished self-insight and disinhibition are not encompassed by the BPRS. Consequently, we have developed the Neurobehavioural Rating Scale (NRS) which retains many BPRS scales in original or revised form in addition to scales which evaluate behavioural manifestations of traumatic brain injury. We administered the NRS to closed head injury patients who were heterogeneous with respect to severity, chronicity and type of brain injury. In this paper we report (1) data bearing on the inter-rater reliability of the NRS; (2) the results of factor analysis of NRS scores which disclosed the major, nonredundant dimensions common to most of the items comprising the Scale; (3) the effects of severity and chronicity of head injury on NRS scores.

\section{Patients and methods}

\section{Patients}

To investigate the inter-rater reliability and validity of the NRS at various stages of recovery after hospitalisation for closed head injury representing a wide range of severity, we studied 101 patients (age range 16 to 51 years) provided that there was no antecedent history of alcoholism, drug abuse, head injury or other neuropsychiatric disorder. Demographic and clinical features of the patients are summarised in table 1 . Motor vehicle accidents produced most of the injuries in our series. In this study we classified closed head injury as mild, moderate or severe primarily on the basis of the post-resuscitation Glasgow Coma Scale (GCS) ${ }^{28}$ score obtained in the emergency room (table 1 ). With respect to minor head injury (that is, loss of consciousness for $\leqslant 30$ minutes, GCS score of 13-15 on hospital admission, no dete- 
rioration to a GCS score $<13$, and normal findings on CT and neurological examinations), we employed a cut-off injury-test interval of at least one month for the subacute vs chronic distinction. For moderate head injury, that is, GCS score on admission of 9-12 with no further deterioration (or 13-15 in a patient with an intracranial mass lesion) and severe closed head injury (that is, GCS score $\leqslant 8$ on admission) we used the first examination within 3 months of injury as a subacute assessment with the exception of patients who emerged from a prolonged period of impaired consciousness and were first testable more than 3 months after injury. Follow-up data to assess long term outcome were obtained at least 6 months after moderate or severe closed head injury.

The subacute head injured patients $(n=63)$ included 48 consecutive admissions (who satisfied the aforementioned criteria) to the Neurosurgery service at The University of Texas Medical Branch, Galveston, whom we examined at bedside as soon as they were capable of cooperating with the interviewer, irrespective of whether they were in PTA, which we assessed by administering a. brief questionnaire of orientation to time, place and person and memory for events related to the injury and hospitalisation. ${ }^{29}$ The remaining 15 subacute closed head injury patients were examined while they were hospitalised on the Rehabilitation service, Medical Center Del Oro, Houston, Texas. Patients whom we examined during the chronic stage of recovery included 19 patients who returned to the Division of Neurosurgery for ongoing follow-up studies, 18 cases enrolled in a residential cognitive and psychosocial rehabilitation programme at the Transitional Learning Community in Galveston and a single patient at the Medical Center Del Oro, Houston. In view of the referral pattern to the residential programme in Galveston of patients with persisting disability secondary to cognitive and/or psychosocial problems long after severe head injury, we treated their data separately from other severely injured patients (table 1).

As shown in table 1, the proportions of patients studied during the subacute vs chronic stages of recovery were comparable for mild and severe (consecutive) injuries, whereas the preponderance of moderate injuries were evaluated within 3 months of injury. In addition, we analysed the effect of chronicity of closed head injury in a group of patients whom we studied during both subacute and follow-up stages of recovery.

Serial GCS scores were recorded prospectively in the patients studied on the Neurosurgery service and at the Medical Center Del Oro. Hospital records were obtained for the patients enrolled in the Transitional Learning Community. We defined the duration of impaired consciousness as the interval from the time of injury until the patient consistently obeyed commands. Computed tomographic (CT) and surgical findings were used to classify the patients as "focal", that is, hemispheric mass lesion (left, right or bilateral) apart from a punctate haemorrhage or diffuse brain injury (that is, normal CT findings, isolated punctate lesion or abnormality confined to evidence of cerebral swelling) while recognising that diffuse effects are commonly associated with focal haematomas or contusions.

\section{Methods}

Neurobehavioural Rating Scale. (NRS) The 27 scales comprising the NRS are depicted in the Appendix. To obtain uniform data on which to base behavioural ratings, we employed a brief structured interview (Appendix) which included a brief test of orientation and memory for recent events, ${ }^{29}$ a review of postconcussional symptoms and emotional state, questions pertaining to proverbs, focused attention and information processing (serial 7s), attitude towards hospital staff (that is, irritability, hostility, misinterpretation of actions by others, suspiciousness), capacity for self-insight and long-range planning and delayed recall of three objects which were presented at the beginning of interview. Observations during the examination which were pertinent to the patient's alertness, distractibility, intrusion of irrelevant material, coherence of conversation, physical signs and verbalisation of anxiety, visible signs of tension, disinhibitory behaviour or agitation, disturbance of mood, motor behaviour and expressive/receptive language functioning were recorded and considered in the NRS ratings. Ratings of fatiguability and motivation reflected the patient's stamina and apparent effort on the mental status tasks (for example, serial 7s) independent of the level of performance.

Pilot data on the NRS were collected to identify ambiguities in terminology of the items and differences in interpretation by various examiners. Discussion of disparities in ratings after interviewing pilot patients led to revisions of the test items and development of a guide for interviewers before undertaking the present study.

Of the 101 patients included in this study, 77 were examined concurrently and evaluated by pairs of interviewers who first discussed their observations to verify that they recorded the same data before independently assigning NRS ratings. In the present study, 43 of the closed head injury patients were concurrently examined by one pair of interviewers (KG and RS), a clinical neuropsychologist and neurological nurse, respectively, and a second pair of interviewers (KG and WH, a research associate in neuropsychology) collected data on 34 head injured patients (KG was one of the interviewers in all 77 cases).

\section{Results}

\section{Inter-rater reliability}

We assessed the inter-rater reliability for the NRS by computing the Pearson correlation coefficient between the total NRS scores (sum scores for the 27 items) for each pair of interviewers. Analysis of the ratings by $K G$ and $R S$ (Pair $A$ ) who concurrently interviewed, but independently rated 43 of the patients yielded a highly significant correlation coefficient of $0.90, p<0.001$. A similar analysis for the total NRS scores of 34 other closed head injury patients who were concurrently interviewed by $\mathrm{KG}$ and WH (Pair B) also revealed a significant correlation $(r=0.88, p<0.001)$. To evaluate the magnitude of disagreement between interviewers for individual items we considered disparities in scores which could potentially influence clinical assessment or management of the patient. Consequently, we analysed inter-rater disagreement across three major categories of disturbance on each of the 27 NRS scales, that is, none/mild, moderate and severe. Accordingly, 
Table 2 Principal component analysis of neurobehavioural rating scale data (with varimax rotation) $(n=101)$

\begin{tabular}{|c|c|c|c|}
\hline $\begin{array}{l}\text { Rotated Factor Loadings* } \\
\text { Variable }\end{array}$ & $\begin{array}{l}\text { Factor I } \\
\text { (Cognition/Energy) }\end{array}$ & $\begin{array}{l}\text { Factor II } \\
\text { (Metacognition) }\end{array}$ & $\begin{array}{l}\text { Factor III } \\
\text { (Somatic/Anxiety) }\end{array}$ \\
\hline $\begin{array}{l}\text { Inattention } \\
\text { Somatic Concern } \\
\text { Disorientation } \\
\text { Anxiety } \\
\text { Expressive Deficit } \\
\text { Emotional Withdrawal } \\
\text { Concept. Disorganisation } \\
\text { Disinhibition } \\
\text { Guilt Feelings } \\
\text { Memory Deficit } \\
\text { Agitation } \\
\text { Inaccurate Self-Appraisal } \\
\text { Depressive Mood } \\
\text { Hostility/Uncooperative } \\
\text { Decreased Initiative } \\
\text { Suspiciousness } \\
\text { Fatiguability } \\
\text { Hallucinatory Behaviour } \\
\text { Motor Retardation } \\
\text { Unusual Thought Content } \\
\text { Blunted Affect } \\
\text { Excitement } \\
\text { Poor Planning } \\
\text { Lability of Mood } \\
\text { Tension } \\
\text { Comprehension Deficit }\end{array}$ & $\begin{array}{r}0.516 \\
-0.203 \\
0.766 \\
-0.224 \\
0.289 \\
0.719 \\
0.589 \\
-0.188 \\
-0.230 \\
0.623 \\
0.070 \\
0.411 \\
0.227 \\
0.154 \\
0.457 \\
0.052 \\
0.572 \\
0.004 \\
0.567 \\
0.060 \\
0.648 \\
-0.109 \\
0.377 \\
0.024 \\
0.060 \\
0.302\end{array}$ & $\begin{array}{r}0.463 \\
0.251 \\
0.134 \\
-0.051 \\
0.121 \\
-0.038 \\
0.491 \\
0.698 \\
0.100 \\
0.206 \\
0.737 \\
0.621 \\
-0.122 \\
0.082 \\
-0.021 \\
0.189 \\
0.041 \\
-0.039 \\
-0.039 \\
0.741 \\
-0.064 \\
0.761 \\
0.619 \\
0.074 \\
-0.024 \\
-0.026\end{array}$ & $\begin{array}{r}-0.068 \\
0.346 \\
-0.045 \\
0.575 \\
-0.634 \\
0.137 \\
-0.117 \\
-0.045 \\
0.226 \\
-0.095 \\
0.059 \\
-0.183 \\
0.407 \\
0.397 \\
0.412 \\
0.442 \\
-0.119 \\
0.068 \\
-0.030 \\
0.119 \\
0.217 \\
-0.121 \\
-0.093 \\
0.186 \\
0.341 \\
-0.579\end{array}$ \\
\hline
\end{tabular}

* Boldface values indicate the factor to which the variables were assigned except for Expressive and Comprehension Language deficits which had strong negative loadings on Factor III and were consequently considered as a fourth factor.

disagreement by one category of abnormality between the two examiners (Pair A) who concurrently interviewed 43 patients was on the average $6.4 \%$ for the 27 NRS items while $2.7 \%$ of their ratings differed by two categories. Thus, $89.9 \%$ of the NRS ratings given by the interviewers in Pair A were within the same broad category of abnormality. The corresponding rate of disagreement for interviewer Pair B was $3.9 \%$ for disparities by one category, whereas there were no disagreements as large as two categories, that is, the average rate of agreement was $96 \cdot 1 \%$ for interviewer Pair B.

\section{Principal components analysis of Neurobehavioural Rating Scale}

We performed a principal components analysis (with varimax rotation) of the NRS ratings for the total series of patients $(n=101)$. As depicted in table 2, this analysis disclosed four factor scores which were formed by summing the NRS scores which had the highest loadings on each factor. Factor I ("cognition/energy") consisted of items evaluating the coherence of cognition and efficiency of memory, behavioural slowing (that is, motor retardation) and emotional withdrawal. Factor II ("Metacognition", that is, knowledge of one's cognitive processes) reflects inaccurate self-appraisal, unrealistic planning and disinhibition, features which are frequently ascribed to frontal lobe dysfunction. ${ }^{30}$ Factor-II was also derived from NRS scales which relate unusual thought content (as distinguished from coherence) and excitement. In contrast to the cognitive deficits and behavioural disturbance emphasised by Factors I and II, Factor III ("somatic concern/anxiety") includes physical complaints, anxiety, depression and irritability. Factor IV ("language") consists of the scales for rating expressive and receptive language deficit which had strong negative loadings on Factor III. Two NRS scales (Inattention and Decreased Initiative) had more than one loading and were not specifically related to any single factor. Guilt, Hallucinations and Lability did not load on any factor.

\section{Effects of severity of head injury}

To analyse the effects of severity of head injury we first performed a multivariate analysis of variance (MANOVA) on the NRS factor scores of the four groups of patients, that is, mild injury, moderate injury, severe injury, severe injury-rehabilitation. We found that the overall effect for severity of head injury was significant, Wilks lambda $=\mathbf{0} \cdot 798$, approximate $F(12,249), p=0.042$. Table 3 presents the factor score means and shows a pattern of greater disturbance as a function of severity of injury on Factors I (cognition/energy), II (metacognition) and IV (language). However, Factor III (somatic concern/anxiety) ratings were unrelated to severity of closed head injury. Although a main effect of acute injury severity was confirmed overall on Factors II and IV (table 3), there was a nonsignificant trend in 
Table 3 Analysis of the effect of severity of head injury on factor scores $\dagger$

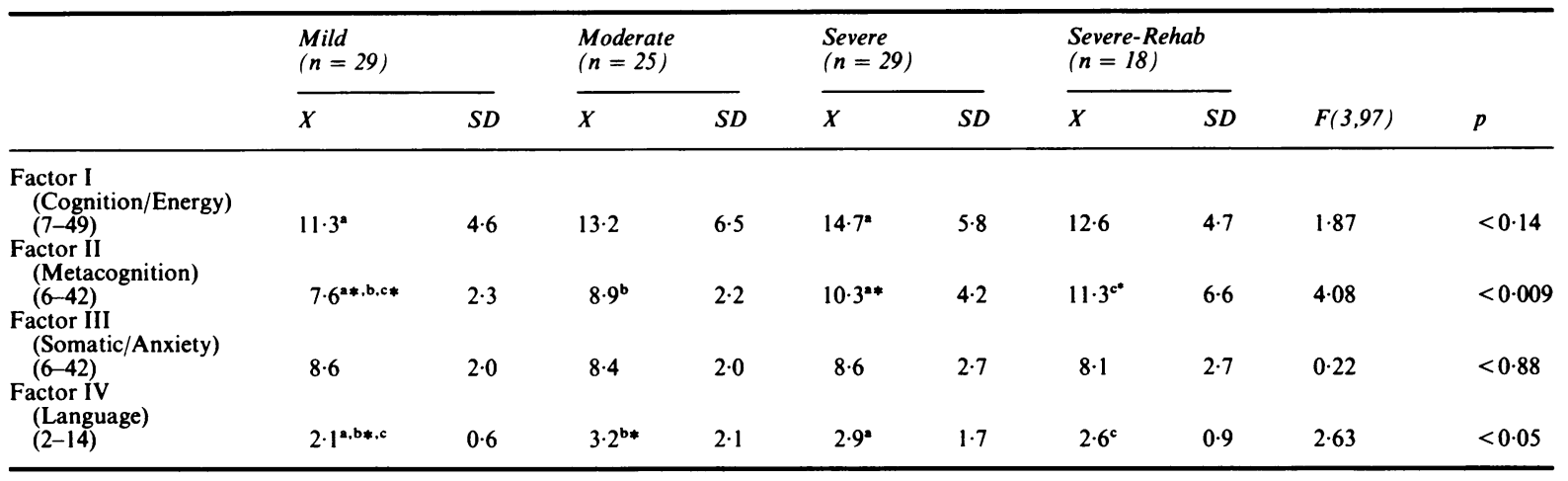

†Mean scores sharing a common superscript letter were significantly different $(\mathrm{p}<0.05)$ according to univariate $\mathrm{F}$ test. The possible range in score is shown in parentheses. A higher score denotes more abnormal behaviour.

*The mean scores of groups sharing a common asterisk were significantly different after applying the Bonferroni adjustment to control for the multiplicity of comparisons (for 0.05 level, $p<0.002$ ).

the predicted direction on Factor I which reflected ratings of more prominent conceptual disorganisation and psychomotor retardation in patients whose initial GCS scores were 8 or less. In contrast, there was no consistent pattern with respect to severity of acute head injury across the variables comprising Factor III.

To explore the sensitivity of individual NRS variables to severity of acute closed head injury, we performed MANOVAs on these measures for each factor. The figure depicts the profile of NRS scores from the four groups of head injured patients. The individual NRS variables are grouped according to their strongest factor loads. Significant main effects (MANOVAs) for severity of closed head injury are depicted above their respective scales. Among the variables loading on Factor I, Conceptual Disorganisation was significantly related to severity of acute injury. As depicted in the figure, NRS scores comprising Factor II which differentiated the severely injured patients include Inaccurate Self-Appraisal and Poor Planning. Although the effect of severity of injury was not significant for Factor III, ratings of apparent Tension were related to the closed head injury classification. The figure also shows a relationship of Expressive, but not Receptive Language deficit to severity of injury. In contrast to the direct relationship between ratings of the aforementioned disturbances and severity of acute closed head injury, the figure shows a dissociation in the direction of more impressive Somatic Concern, Anxiety and Inattention in patients who sustained mild head injuries as compared to the other groups. Pairwise contrasts confirmed that the mild closed head injury patients expressed greater Somatic Concern than the severely injured patients in the residential treatment centre $(t=2.43,45$ d.f., $p<0.02)$, whereas similar comparisons did not reach significance for Anxiety or Inattention.
The five variables plotted in part $\mathrm{c}$ right of the figure were found in the principal components analysis to load on two factors (for example, Inattention) or were rarely rated as present (for example, Guilt). Of these isolated NRS variables, analysis of variance disclosed that the effect of severity of injury approached significance for Motivation, $F(3,97)=$ $2.43, p<0.07$. We added a scale to rate Articulation Disturbance (please see Appendix) apart from Expressive Language defect midway during the data collection because of the presence of dysarthria which detracted from the intelligibility of communication in severely injured patients whose Expressive Language was intact. Consequently, we obtained ratings of Articulation Disturbance in only 53 of the closed head injury patients ( 24 severe-consecutive, 8 severe closed head injury patients enrolled in residential rehabilitation, 8 moderate injuries and 13 mild cases). Consistent with our findings that Articulation Disturbance was confined to severely injured patients, a one-way analysis of variance yielded an effect of severity which approached significance, $F(3,49)=$ $2.55, \mathrm{p}<0.07$. Pairwise contrasts disclosed that the patients in the residential rehabilitation programme had worse articulation than patients with mild ( $\mathrm{p}<$ $0.02)$ or moderate $(p<0.04)$ injuries.

Serial administration of the Neurobehavioural Rating Scale to depict recovery from closed head injury

In the course of ongoing longitudinal studies of consecutive head injured patients hospitalised on the neurosurgery service (excluding cases with pre-existing neuropsychiatric disorder), we obtained a baseline NRS typically during the acute hospitalisation (mean injury-examination interval $=23.9$ days, $S D=37 \cdot 5$ ) and a follow-up examination at least one month after injury (mean $=139$ days, $S D=1.33)$ in 20 cases $(15$ men, 5 women). The mean age of these patients at the time of injury was $27 \cdot 1(\mathrm{SD}=10 \cdot 2)$; their mean edu- 
(a)
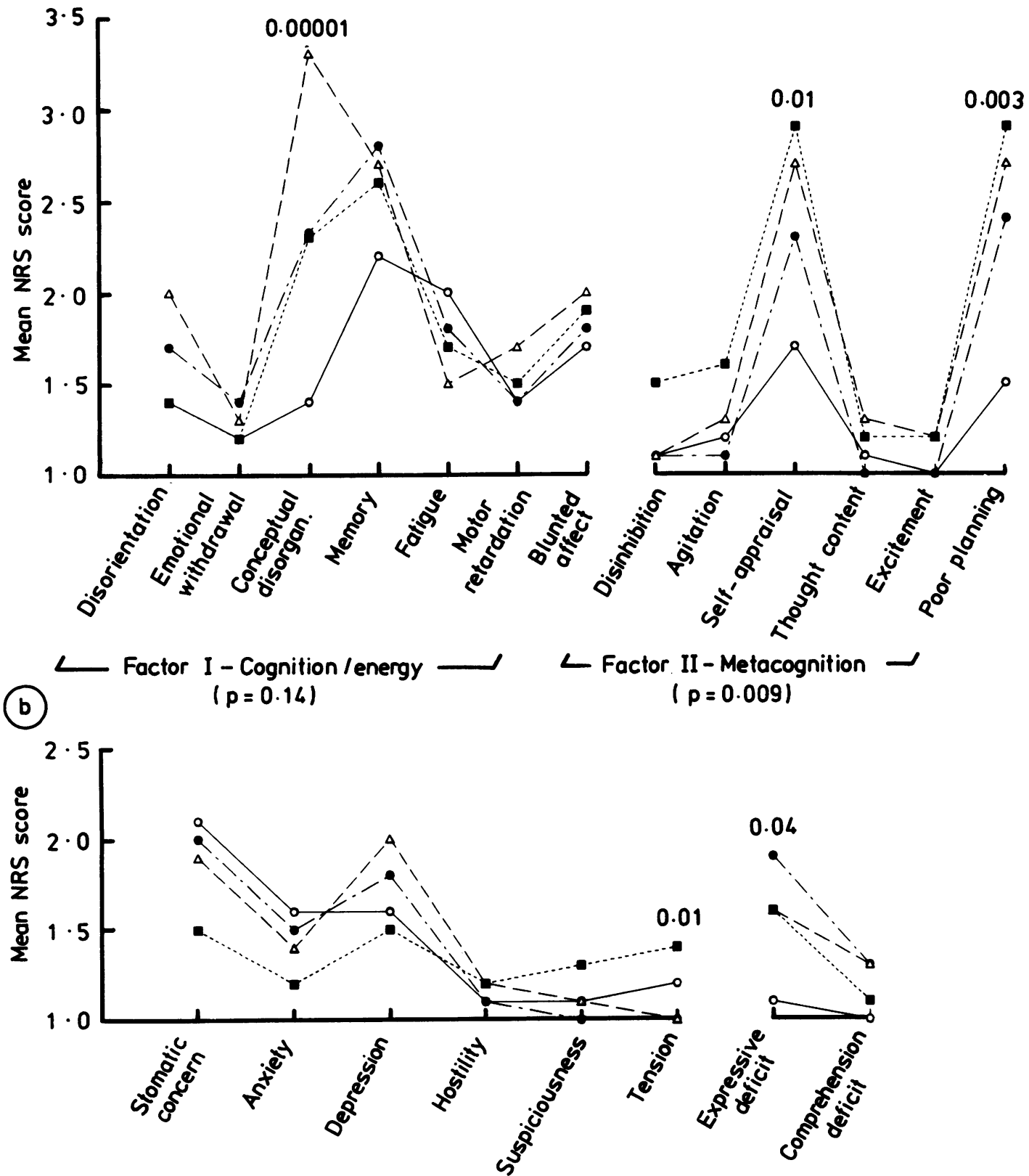

$\longleftarrow$ Factor III Somatic / anxiety

\section{(Factor IV Language ) $(p=0.054)$}

Fig Mean scores for the 27 Neurobehavioural Rating Scale (NRS) variables plotted for the four samples of head injured patients. The NRS variables are grouped according to their loadings on the four factors. Significant main effects of severity of head injury on mean NRS scores are depicted by the probability values above the respective variables. 


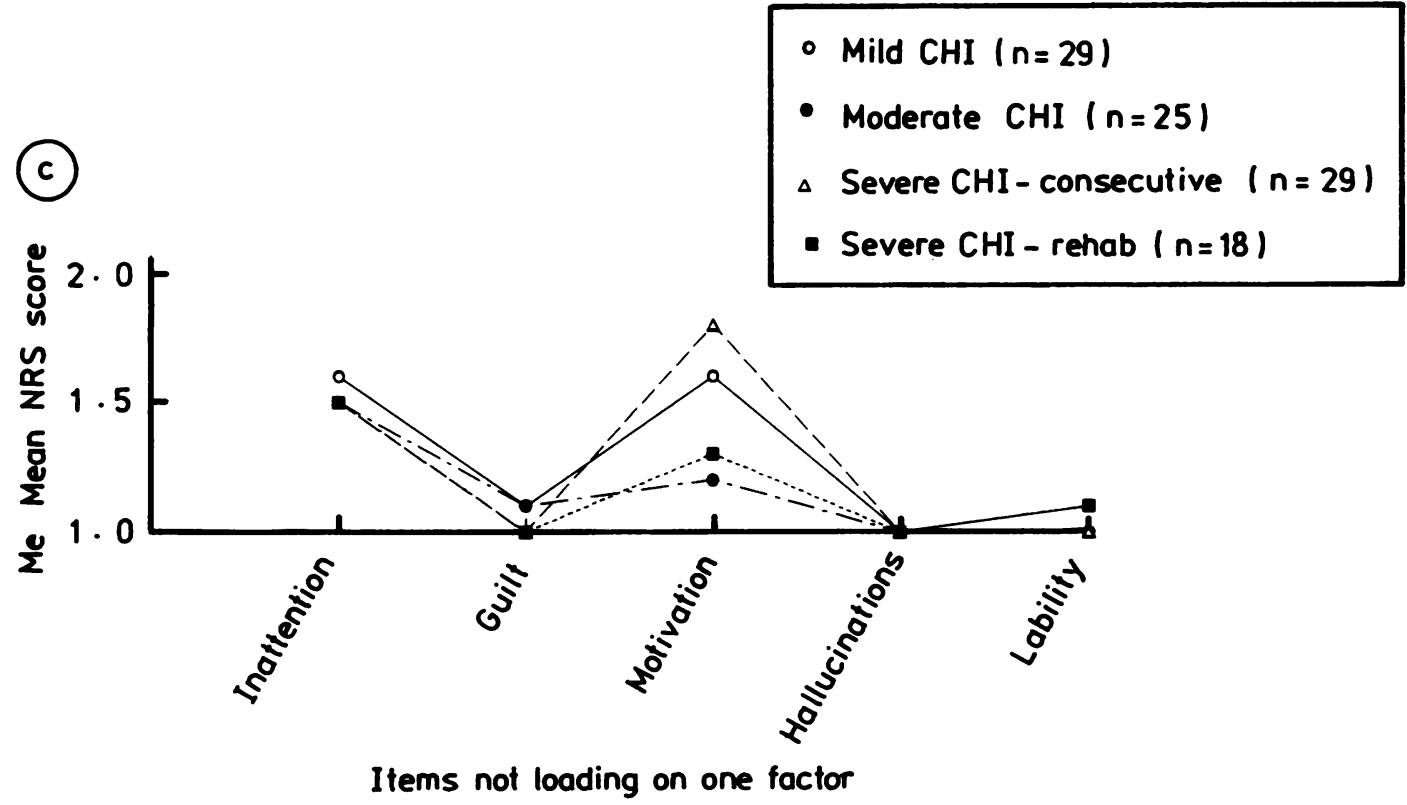

cation was 11.7 years $(\mathrm{SD}=1.9)$. Consistent with the total series, motor vehicle accidents accounted for most of these injuries. The 20 serially studied patients included two cases of mild head trauma, nine patients who sustained moderate closed head injury and nine with severe head injury.

Table 4 summarises the factor scores of these patients at baseline and follow-up. A repeated measures MANOVA revealed significant overall resolution of behavioural disturbance as reflected by a reduction in the total scores by the time of follow-up, $\mathrm{F}(1,19)=21.4, \mathrm{p}<0.0002$ which was also confirmed on Factors I and II and approached significance on Factor IV.

\section{Effects of frontal lobe injury}

To investigate the role of frontal lobe involvement in neurobehavioural sequelae of closed head injury, we formed a subgroup of 26 patients ( 16 subacute and 10 chronic cases) in whom CT and/or surgical findings disclosed a contusion or haematoma situated entirely or primarily in the frontal lobe(s). We selected cases from the remainder of the series to form a non-frontal comparison group (16 subacute, 10 chronic patients) in whom CT and/or surgical findings showed no evidence of a frontal lobe lesion. This non-frontal comparison group consisted of 17 patients with diffuse injury and nine cases with temporal and/or parietal lesions. We recognise that this localisation of focal lesion is flawed by the presence of occult lesions of the cerebral white matter which may have been undetected by $\mathrm{CT}^{33}$ and a varying degree of concomitant diffuse brain injury. Consequently, the distinction between the two subgroups may rest primarily on the extent of frontal lobe injury. In view of the importance of matching the two subgroups with respect to demographic variables, there was an insufficient number of non-frontal patients with contusions or haematomas available for comparison. Consequently, most of the non-frontal comparison group had diffuse injuries with the exception of the cases with temporal and/or parietal lesions.

As summarised in table 5, the frontal and nonfrontal subgroups were comparable with respect to age, education, initial GCS score recorded on hospital admission and the duration of impaired consciousness, that is, the interval during which the patient was unable to obey commands.

We compared the NRS scores of the frontal and non-frontal subgroups by performing a one-way analysis of variance on the factor scores. As summarised in table 5, the trends for higher (that is, more abnormal) scores in the non-frontal group on the Cognitive-Energy and Somatic-Anxiety factors were not significant nor was the pattern of more impaired Metacognition (Factor II) in the subgroup of patients with frontal lobe injury. However, the Factor I-Factor II difference score was greater in the nonfrontal group as compared to patients with frontal lobe lesions (table 5) implying that the pattern of cognitive and behavioural features exhibited by these two groups differed. 
Table 4 Changes in Neurobehavioural Rating Scale Scores from initial hospitalisation for Closed Head Injury to follow-up examination $(n=20)$

\begin{tabular}{|c|c|c|c|c|c|c|}
\hline & \multicolumn{2}{|c|}{ Baseline } & \multicolumn{2}{|c|}{ Follow-up } & \multirow[b]{2}{*}{$F(1,19)$} & \multirow[b]{2}{*}{$p$} \\
\hline & $x$ & $S D$ & $X$ & $S D$ & & \\
\hline $\begin{array}{l}\text { Factor I (Cognition/Energy) } \\
\text { Factor II (Metacognition) } \\
\text { Factor III (Somatic/Anxiety) } \\
\text { Factor IV (Language) }\end{array}$ & $\begin{array}{r}14 \cdot 8 \\
9 \cdot 9 \\
9 \cdot 8 \\
4 \cdot 1\end{array}$ & $\begin{array}{l}5 \cdot 5 \\
2 \cdot 7 \\
3 \cdot 0 \\
2 \cdot 3\end{array}$ & $\begin{array}{r}11 \cdot 6 \\
8 \cdot 4 \\
9 \cdot 1 \\
3 \cdot 3\end{array}$ & $\begin{array}{l}3 \cdot 8 \\
2 \cdot 3 \\
3 \cdot 0 \\
1 \cdot 6\end{array}$ & $\begin{array}{r}16 \cdot 5 \\
15 \cdot 7 \\
0 \cdot 7 \\
3 \cdot 5\end{array}$ & $\begin{array}{l}<0.007 \\
<0.008 \\
\text { NS } \\
<0.08\end{array}$ \\
\hline
\end{tabular}

Table 5 Comparison of demographic variables and Neurobehavioural Factor Scores in the Frontal vs Nonfrontal Groups

\begin{tabular}{|c|c|c|c|c|c|c|}
\hline & \multicolumn{2}{|c|}{ Frontal $(n=26)$} & \multicolumn{2}{|c|}{ Nonfrontal $(n=26)$} & \multirow[b]{2}{*}{$F(1,50)$} & \multirow[b]{2}{*}{$p$} \\
\hline & $X$ & $S D$ & $X$ & $S D$ & & \\
\hline $\begin{array}{l}\text { Age } \\
\text { Education (yr) } \\
\text { GCS Score } \\
\text { Duration of Impaired Consciousness (days) } \\
\text { Factor I (Cognition/Energy) } \\
\text { Factor II (Metacognition) } \\
\text { Factor III (Somatic/Anxiety) } \\
\text { Factor IV (Language) } \\
\text { Factors I-II Difference Score }\end{array}$ & $\begin{array}{r}23 \cdot 7 \\
11 \cdot 4 \\
9 \cdot 4 \\
16 \cdot 1 \\
12 \cdot 0 \\
10 \cdot 5 \\
7.9 \\
2.9 \\
1 \cdot 5\end{array}$ & $\begin{array}{r}6 \cdot 1 \\
2 \cdot 9 \\
4 \cdot 1 \\
26 \cdot 3 \\
5 \cdot 0 \\
6 \cdot 4 \\
1.6 \\
1.6 \\
6 \cdot 2\end{array}$ & $\begin{array}{r}24 \cdot 0 \\
12 \cdot 1 \\
9 \cdot 1 \\
17 \cdot 3 \\
14 \cdot 2 \\
9 \cdot 0 \\
8 \cdot 5 \\
2 \cdot 5 \\
5 \cdot 2\end{array}$ & $\begin{array}{r}6 \cdot 7 \\
2 \cdot 0 \\
3 \cdot 5 \\
32 \cdot 9 \\
6 \cdot 1 \\
2 \cdot 5 \\
3 \cdot 2 \\
0.9 \\
5 \cdot 2\end{array}$ & $\begin{array}{l}0.02 \\
0.75 \\
0.07 \\
0.02 \\
1.20 \\
1.17 \\
0.78 \\
0.91 \\
5.30\end{array}$ & $\begin{array}{l}\text { NS } \\
\text { NS } \\
\text { NS } \\
\text { NS } \\
\text { NS } \\
\text { NS } \\
\text { NS } \\
\text { NS } \\
<0.03\end{array}$ \\
\hline
\end{tabular}

Effects of demographic features on NRS scores

We explored the presence of differences in NRS scores related to age and sex. As suggested by the variation in age across the four groups of closed head injury patients (table 1), there was a modest, albeit significant negative correlation (Pearson correlation coefficient $=-0.18, p<0.04)$ between severity of injury (that is, duration of impaired consciousness) and age. Consequently, we performed partial correlations between age and the NRS variables to adjust for this index of injury severity. Most of the partial correlation coefficients showed no relationship between age and residual behavioural disturbance. However, significant correlations were obtained for Somatic Concern $(r=0.26, p<0.006)$ and Tension $(\mathrm{r}=-0.26, \mathrm{p}=0.006)$.

To assess the presence of a gender effect on neurobehavioural sequelae, we first verified that there was no difference in severity of injury, interval since injury, age or education between the men and women. A MANOVA on the NRS variables disclosed an overall effect of sex which approached significance. Wilks lambda $=0.641$, approximate $F(26,74)=$ $1.59, \mathrm{p}<0.07$. Univariate contrasts indicated that women exhibited more severe depression (mean = $2 \cdot 4, \mathrm{SD}=1 \cdot 1)$ than men $($ mean $=1.5, \mathrm{SD}=0.9)$, approximate $F(26,74)=13.77, p<0.001$. Other differences in NRS scores between men and women were relatively small and of only marginal significance.

\section{Discussion}

Recent investigations have elucidated the psychosocial outcome of nonmissile head injury primarily by interviewing relatives and obtaining their ratings of the patient on various scales of adaptive behaviour. ${ }^{9-16}$ These studies have confirmed that behavioural disturbance frequently persists after severe closed head injury and is especially stressful for the patient's family..$^{9-13}$ Self-administered tests such as the MMPI have also documented residual emotional disturbance after head injury and its relationship to cognitive impairment. ${ }^{24}$ However, head injured patients are frequently unable to complete selfadministered questionnaires during the early stages of recovery and their diminished insight can compromise the validity of these tests given at later stages of outcome. While reports by relatives contribute immensely to characterising the long-term psychosocial effects of head injury, a scale such as the NRS could also aid clinicians in monitoring behavioural changes during the initial hospitalisation, inpatient and outpatient rehabilitation.

Our findings support the overall inter-rater reliability of the NRS, indicating that it is comparable to that of the BPRS in head injured patients. ${ }^{1}$ The present study also supports the validity of the NRS, at least with respect to the effects of severity and chronicity of brain injury. Of the four factors derived from the NRS variables, Metacognition, that is, the 
capacity for self-evaluation of abilities, monitoring and regulating impulses and formulating realistic plans, was particularly related to severity of injury. Notwithstanding the differences in chronicity and selectivity between the consecutive severe closed head injury patients and the severely injured cases attending the residential rehabilitation programme, their profiles of neurobehavioural disturbance were remarkably similar. Both groups of severe head injuries exhibited conceptual disorganisation, disinhibition, diminished self-insight and poor planning. Expressive language defects characterised primarily by word finding difficulty and anomia were also present to a mild degree in both groups.

Of the NRS variables which were related to severity of acute injury, only conceptual disorganisation was derived from the original BPRS. Our data corroborate the results obtained with the BPRS ${ }^{1}$ indicating that conceptual disorganisation is a prominent feature of severe closed head injury. However, other variables derived from the BPRS (for example, motor retardation, blunted affect) which Levin and Grossman found to be sensitive to severity of injury were not confirmed in the present study.

Constraints on the administration of the NRS to patients during the early stages of recovery include a reduced behavioural repertoire imposed by physical limitations (for example, assessment of motor retardation in a bedridden patient) and the hospital environment. When examined later in the course of recovery, a wider range of behavioural manifestations may be displayed because of greater mobility; more opportunities for social interaction and reaction to frustrations involved in rehabilitation and reintegration in the family and community.

Our severe closed head injury patients were generally studied at least 6 months after injury. In comparison with follow-up data obtained in cases of minor head injury, the severely injured group exhibited more impressive conceptual disorganisation, inaccurate self-insight, decreased initiative/motivation and poor planning. These findings, which were based on a structured interview and mental status examination, reflect residual difficulty in the interpretation of proverbs, perseveration, difficulty in filtering tangential material and failure to appreciate the cognitive defects resulting from the injury. Further, patients sustaining severe head injury demonstrated unrealistic planning (for example, reflected by boastfulness) when asked about their goals following discharge from the hospital or rehabilitation programme.

The prominent neurobehavioural sequelae of severe closed head injury in the present study are reminiscent of the prevailing concept of a "frontal lobe syndrome". ${ }^{30-32}$ Although CT scanning disclosed focal frontal lobe lesions in one-fourth of our series, recent studies suggest that magnetic resonance imaging (MRI) can visualise injury and degenerative changes in this region which are otherwise undetected. ${ }^{33}$ Allowing for the technical limitations in attempting to differentiate our patients according to localisation of focal hemispheric lesion, our results offer preliminary support for a disproportionate impairment of metacognition in patients sustaining frontal lobe injury. Patients with diffuse closed head injury or extrafrontal lesions tended to exhibit more cognitive problems and diminished energy despite relatively intact capacity for self-monitoring and evaluation of cognitive processes. To analyse further the effects of frontal lobe injury on the neurobehavioural sequelae of closed head injury, lesion size, initial GCS score, duration of impaired consciousness and PTA should be controlled in addition to relevant subject variables (age, sex, education) for comparison with groups of patients with temporal or parietal lobe lesions. Apart from focal frontal lobe lesions, shearing, tearing and stretching of axons immediately on impact $^{3435}$ could disrupt connections between the prefrontal region and both the limbic system and other areas of association corte ${ }^{30}$ which are essential to complex integration of information for problemsolving and "executive" functions such as planning and initiation of activities as well as modulation of emotion.

Caution is advised before applying the NRS in other clinical or research settings. First, preliminary training of interviewers through concurrent assessment of pilot patients and discussion of disagreements with respect to behavioural observations and interpretation of the NRS variables are essential to developing a common frame of reference and satisfactory inter-rater reliability. Although we administered a specific structured interview to all patients studied, we surmise that comparable reliability could be achieved through other interview protocols and by integration of interview data with observations of patients during various therapies associated with rehabilitation. We suggest that a profile of qualitative behavioural manifestations is an important asset of the NRS, particularly with respect to features (for example, planning, self-appraisal) which frequently elude conventional psychometric tests but nevertheless contribute to adaptation in psychosocial and vocational functioning.

Our finding that patients sustaining minor head injury tend to complain of somatic symptoms (for example, dizziness, headaches) to a greater degree than severely injured patients is in accord with other recent evidence ${ }^{15}$ that some sequelae can be interpreted as "intolerances" rather than as indications of disability because they are unrelated to severity of injury or to functional outcome. Although the followup interval was longer in our severe closed head injury groups than in the mild head injuries, we postulate that their lack of somatic complaints (for example, note in the figure the low somatic concern expressed by severely injured patients enrolled in rehabilitation) 
reflects inaccurate self-appraisal, apparent denial or at least unawareness of physical disability and verbal expansiveness.

How distinctive is the profile of neurobehavioural disturbance after severe nonmissile head injury? Collection of NRS data in a larger series of severely injured patients in the ongoing, four centre National Traumatic Coma Data Bank ${ }^{36}$ should provide information bearing on the relationship of the pattern of behavioural disturbance in relation to the lateralisation and extent of focal hemispheric injury, severity of diffuse brain injury and individual differences (such as sex, age). In addition, administration of the NRS to patients with other aetiologies of brain damage (for example, stroke, epilepsy, degenerative dementia) is necessary to assess the distinctiveness of neurobehavioural sequelae of head injury.

This research was supported by NIH grants NS 07377, A Center for the Study of Central Nervous System Injury; NS 21889, Javits Neuroscience Investigator Award; NS 9-2314, Comprehensive Central Nervous System Trauma Center; and by grants from the Moody Foundation 84-152 and Dallas Rehabilitation Foundation. We are grateful to $\mathrm{Dr}$ Arthur L Benton for reviewing the manuscript and to Beverly Parman for secretarial assistance.

Portions of this paper were presented at the 13th International Neuropsychological Society Conference on 9 February 1985 in San Diego.

\section{APPENDIX}

NEUROBEHAVIORAL RATING SCALE

H.S. Levin; J.E. Overall, K.E. Goethe, W. High, R.A. Sisson

DIRECTIONS: Place an $X$ in the eppropriate box to represent level of severity of each symptom.

1. INATTENTION/REDUCED ALERTNESS - fails to sustain attention, easily distracted; fails to notice aspects of environment, difficulty directing attention, decreased alertness.

2. SOMATIC CONCERN-volunteers complaints or eleborates ebout somatic symptoms (e.g., headache, dizziness, blurred vision), and about physicat health in general.

3. DISORIENTATION-confusion or lack of proper association for person, place, or time.

4. ANXIETY-worry, fear, overconcern for present or future.

5. EXPRESSIVE DEFICIT-word-finding disturbance, anomia, pauses in speech, effortful and agrammatic speech, circumlocution.

6. EMOTIONAL WITHDRAWAL-lack of spontaneous interaction, isolation, deficiency in relating to others.

7. CONCEPTUAL DISORGANIZATION-thought processes confused, disconnected, disorganized. disrupled; tangential social communication; perseverative.

8. DISINHIBITION-socially inappropriate comments and/or actions, including aggressive/sexual content, or inappropriate to the situation, outbursts of temper.

9. CUILT FEELNGS-self-blame, shame, remorse for past behavior.

10. MEMORY DEFICIT-difficulty learning new information, rapidly forgets recent events, although immediate recall (forward digit span) may be intact.

11. AGITATION-motor manifestations of overactivation (e.9. kicking. arm flailing. picking. rouming. restlessness. talkativeness.)

12. INACCURATE INSIGHT AND SELF-APPRAISAL-poor insight, exaggerated self-opinion, overrates level of ability and underrates personality change in comparison with evaluation by clinicians and family.

13. DEPRESSIVE MOOD-sorrow, sadness, despondency, pessimism.

14. HOSTILITY/UNCOOPERATIVENESS-animosity, irritability, belligerence. disdain for others. defiance of authority.

16. DECREASED INITIATIVE/MOTIVATION-lacks normal initiative in work or leisure, fails to persist in tasks, is reluctant to accept new challenges.

16. SUSPICIOUSNESS-mistrust, belief that others harbor malicious or discriminatory intent.

17. FATIGABIUITY-rapidly fotigues on challenging cognitive tasks or complex activities. lethargic.

18. HALLUCINATOAY BEHAVIOR-perceptions without normal external stimulus correspondence.

19. MOTOR RETARDATION-slowed movements or speech (excluding primary weakness).

20. UNUSUAL THOUGHT CONTENT-unUSual, odd, strange, bizarre thought content.

21. BLUNTED AFFECT_reduced emotional tone, reduction in normal intensity of foelings; flatness.

22. EXCITEMENT -heightened emotional tone, increased reactivity

23. POOR PLANNING-unrealistic goals, poorly formulated plans for the future, disregards prerequisites (e.g., training). fails to take disability into account.

24. LABILTY OF MOOD-sudden change in mood which is disproportionate to the situation.

25. TENSION-postural and facial expression of heightened tension, without the necessity of excessive activity involving the limbs or trunk.

26. COMPREHENSION DEFICIT-difficulty in understanding oral instructions on single or multistage commands.

27. SPEECH ARTICULATION DEFECT-misarticulation, slurring or substitution of sounds which affect intelligibility (rating is independent of linguistic content.)

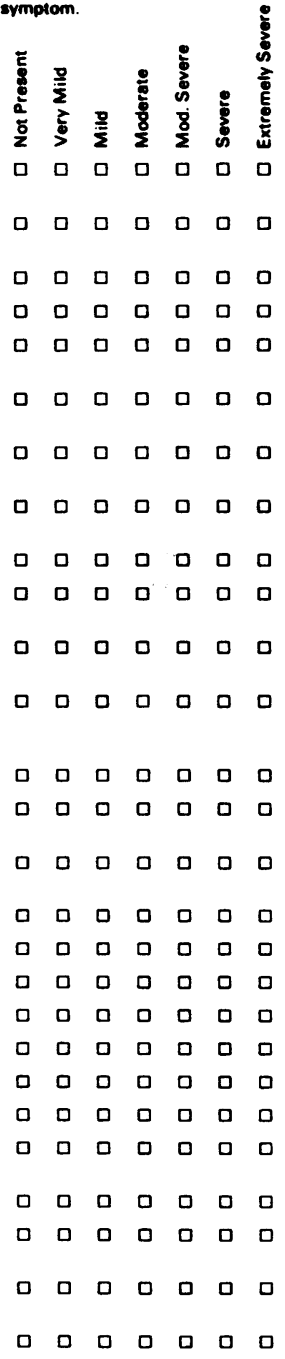




\section{References}

1 Levin HS, Grossman RG. Behavioral sequelae of closed head injury. A quantitative study. Arch Neurol 1978;35:720-7.

2 Lishman WA. The psychiatric sequelae of head injury: a review. Psychol Med 1973;3:304-18.

3 Ruesch J. Intellectual impairment in head injuries. Am J Psychiatry 1944;100:480-96.

4 Ruesch J, Bowman KM. Prolonged post-traumatic syndromes following head injury. Am J Psychiatry 1945;102:145-63.

5 Schilder P. Psychic disturbances after head injuries. Am J Psychiatry 1934;91:155-88.

6 Schnaper N. The psychological implications of severe trauma: emotional sequelae to unconsciousness. A preliminary study. J Trauma 1975;15:94-8.

7 Stern JM. Cranio-cerebral injured patients. A psychiatric clinical description. Scand J Rehab Med 1978;10:7-10.

8 Jennett B, Snoek J, Bond MR, Brooks N. Disability after severe head injury: observations on the use of the Glasgow Outcome Scale. J Neurol Neurosurg Psychiatry 1981;44:285-93.

9 Brooks DN, McKinlay W. Personality and behavioural change after severe blunt head injury-a relative's view. J Neurol Neurosurg Psychiatry 1983;46:336-44.

10 Fordyce DJ, Roueche JR, Prigatano GP. Enhanced emotional reactions in chronic head trauma patients. $J$ Neurol Neurosurg Psychiatry 1983;46:620-4.

11 Livingston MG, Brooks DN, Bond MR. Three months after severe head injury: psychiatric and social impact on relatives. $J$ Neurol Neurosurg Psychiatry 1985;48:870-5.

12 Livingston MG, Brooks DN, Bond MR. Patient outcome in the year following severe head injury and relatives' psychiatric and social functioning. J Neurol Neurosurg Psychiatry 1985;48:876-81.

13 McKinlay WW, Brooks DN, Bond MR, Martinage DP, Marshall MM. The short-term outcome of severe blunt head injury as reported by relatives of the injured persons. J Neurol Neurosurg Psychiatry 1981;44:727-33.

14 Oddy M, Coughlan T, Tyerman A, Jenkins D. Social adjustment after closed head injury: a further followup seven years after injury. $J$ Neurol Neurosurg Psychiatry 1985;48:564-8.

15 van Zomeren AH, Van Den Burg W. Residual complaints of patients two years after severe head injury. $J$ Neurol Neurosurg Psychiatry 1985;48:21-8.

16 Weddell R, Oddy M, Jenkins D. Social adjustment after rehabilitation: a two year follow-up of patients with severe head injury. Psychol Med 1980;10:257-63.

17 Cassileth BR, Lusk EJ, Strouse TB, Miller DS, Brown LL, Cross PA, Tenaglia AN. Psychosocial status in chronic illness. A comparative analysis of six diagnostic groups. N Engl J Med 1984;311:506-10.
18 Gronwall D, Wrightson P. Delayed recovery of intellectual function after minor head injury. Lancet 1974;ii:605-9.

19 Levin HS, Mattis S, Ruff RM, et al. Neurobehavioral outcome of minor head injury: a three center study. $J$ Neurology (in press).

20 Rutherford WH, Merrett JD, McDonald JR. Sequelae of concussion caused by minor head injuries. Lancet 1977;i:1-4.

21 Walker AE. Long term evaluation of the social and family adjustment to head injuries. Scand $J$ Rehab Med 1972;4:5-8.

22 Dahlstrom WG, Welsh GS, Dahlstrom LE. An MMPI handbook. Vol. 1. Clinical Interpretation. Minneapolis: University of Minnesota Press, 1972.

23 Dikmen S, Reitan RM. Emotional sequelae of head injury. Ann Neurol 1977a;2:492-4.

24 Dikmen S, Reitan RM. MMPI correlates of adaptive ability deficits in patients with brain lesions. J Nerv Ment Dis 1977b;165:247-54.

25 Jennett B, Bond $M$. Assessment of outcome after severe brain damage. Lancet 1975;1:480-7.

26 Levin HS, Grossman RG, Rose JE, Teasdale G. Longterm neuropsychological outcome of closed head injury. J Neurosurg 1979;50:412-22.

27 Overall JE, Gorham DR. The brief psychiatric rating scale. Psychol Rep 1962;10:799-812.

28 Teasdale G, Jennett B. Assessment of coma and impaired consciousness: a practical scale. Lancet 1974;2:81-4.

29 Levin HS, O'Donnell VM, Grossman RG. The Galveston orientation and amnesia test: A practical scale to assess cognition after head injury. $J$ Nerv Ment Dis 1979;167:675-84.

30 Nauta WJH. The problem of the frontal lobe. A reinterpretation. J Psychiat Res 1971;8:167-87.

31 Stuss DT, Benson DF. Neuropsychological studies of the frontal lobes. Psychol Bull 1984;95:3-28.

32 Jounadet M, Gazzaniga MS. The frontal lobes. In: Gazzaniga MS, ed. Handbook of Behavioral Neurobiology. New York: Plenum Press, 1979:25-59.

33 Gandy SE, Snow RB, Zimmerman RD, Deck MDF. Cranial nuclear magnetic resonance imaging in head trauma. Ann Neurol 1984;16:254-7.

34 Adams JH, Graham DI, Murray LS, Scott G. Diffuse axonal injury due to nonmissile head injury to humans: an analysis of 45 cases. Ann Neurol 1982;12:557-63.

35 Strich SJ. Diffuse degeneration of the cerebral white matter in severe dementia following head injury. $J$ Neurol Neurosurg Psychiatry 1956;19:163-85.

36 Marshall LF, Becker DP, Bowers SA, Cayard C, Eisenberg HM, et al. The national coma data bank. Part 1: Design, purpose, goals and results. J Neurosurg 1983;59:276-84. 